\title{
A velhice na telenovela brasileira contemporânea: fomento ao debate ${ }^{1}$
}

\author{
Ageing in contemporary Brazilian \\ telenovela: fostering the debate
}

\author{
Gisela G S Castro | ESPM- SP \\ Docente e pesquisadora do Programa de Pos-Graduacao em Comunicacao \\ e Práticas de Consumo ESPM-SP. Graduada em Psicologia (IP/UFRJ), \\ Mestre e Doutora em Comunicacao e Cultura (ECO/UFRJ). \\ E-mail: castro.gisela@gmail.com \\ Maria Aparecida Baccega | PPGCOM ESPM-SP \\ Docente pela ECA/USP; Decana do Programa de Pós-Graduação \\ em Comunicação e Práticas de Consumo da ESPM-SP. \\ E-mail: mabga@usp.br
}

\begin{abstract}
Resumo
O texto apresenta os resultados iniciais de um estudo sobre o tratamento da temática da velhice nas telenovelas brasileiras atuais. Entendemos que as representações sociais funcionam como matrizes simbólicas e comparecem nas práticas cotidianas e nas produçóes midiáticas, sendo importantes na modulação social dos modos de ser e de viver. A complexidade sociocultural está presente na telenovela atual, cujas tramas multifacetadas são elaboradas em sintonia com sondagens de público e os acontecimentos sociais marcantes no momento. Cartografar a maneira como são acionados os arraigados estereótipos e os cambiantes papéis socialmente atribuídos aos mais velhos nas novelas contemporâneas é o objetivo do estudo que discute, dentre outros, o caráter insidioso do idadismo, a violência e a solidariedade na sociedade em relação aos mais velhos.
\end{abstract}

Palavras-Chave: velhice; telenovela brasileira; velhice feminina.

\begin{abstract}
This paper presents preliminary results from an ongoing study on the ways ageing is presented in contemporary Brazilian telenovelas. Social representations function as symbolic matrices embedded in everyday practices and in media productions. They are important in the social modulation of the modes of being and forms of living. Sociocultural complexity is present in today's telenovela. Multifaceted plots are woven in tune with public polls and the most striking social events. This study aims to map the way deep-rooted stereotypes and changing roles socially assigned to older men and women are presented in current telenovelas. Among other aspects, we discuss the insidious nature of ageism, violence and solidarity in society regarding older people.
\end{abstract}

Keywords: ageing; Brazilian telenovela; ageing women. 
Apresentamos neste artigo os primeiros resultados de pesquisa em andamento que se volta para a telenovela e discute a constituição social dos sentidos atribuídos à velhice e aos mais velhos no Brasil contemporâneo. Conforme entendemos, este gênero midiático que protagoniza o cotidiano de amplas parcelas da população de nosso imenso país se desenvolve em permanente interação com o contexto socioeconômico-cultural e contribui na modulação social dos modos de ser e de viver em nossos dias.

Ao examinar as articulaçôes entre este gênero majoritário dentro da ficção televisiva nacional com as temáticas da velhice, destacamos a construção sociocultural do envelhecimento e dos cambiantes papéis socialmente atribuídos aos mais velhos em nosso País. Sabemos que a velhice humana é um fenômeno multifacetado, que não se pode naturalizar como etapa do decurso de uma vida. Em termos etários, trata-se de uma categoria imprecisa cujos contornos náo são exatos e nem muito menos universais. A periodizaçáo da vida obedece a critérios controversos e varia em cada grupo social. Em termos biológicos, constata-se em um mesmo organismo que o envelhecimento de células, órgãos e tecidos envolve ritmos e temporalidades diferenciados. Embora a idade cronológica seja uma importante referência social, "as categorias de idade são construçôes culturais que mudam historicamente (...) e operam recortes no todo social, estabelecendo direitos e deveres diferenciados (...), definindo relaçôes entre geraçóes e distribuindo poder e privilégios" (DEBERT, 2006, p. 53).

Simbolicamente, a velhice pode receber a conotação positiva da sabedoria e do legado da tradição e da memória embora talvez com maior frequência esteja associada ao crepúsculo da vida, ao declínio das funçóes, a várias formas de dependência e finalmente à proximidade da morte. Nesta reflexão ressaltamos o caráter controverso do universo semântico da velhice e destacamos a estreita e nem sempre pacífica convivência entre o natural e o cultural, o individual e o social, a moral conservadora e a ousadia transgressora, o descaso e a compaixão, o preconceito nem sempre explícito, dentre outros fatores.

A questão do preconceito está presente na sociedade, onde se constata uma discriminação muito mais insidiosa contra as mulheres, que costumam ser classificadas pejorativamente como velhas muito mais cedo do que os homens. A pátina do tempo costuma ser percebida como um atributo de charme e estilo no homem maduro, enquanto para a mulher combater os sinais da idade se torna um dever moral no ideário anti-envelhecimento em vigor. Neste ideário, a juventude se descola do patamares etários e passa a ser encarada como um valor, um trunfo a ser exibido em qualquer idade, um imperativo social.

Chama-se idadismo o preconceito com base na idade que fomenta a discriminação etária. Nesse sentido, é também a atitude discriminatória que está na base do bullying social frequentemente praticado contra os mais velhos. Embora lamentável, a nefasta conjugação entre machismo e idadismo ainda prevalece em nossas culturas quando se trata da mulher mais velha.

Dada a prevalência do imperativo da juventude, o velho é sempre o outro e raramente uma categoria de auto-classificação (BEAUVOIR, 1976; DEBERT, 1999). Neri (2007, p. 34) resume a questão ao ponderar que "na velhice, não 
nos reconhecemos velhos e, à medida que envelhecemos, tendemos a fixar em idades cada vez mais avançadas aquela que marca a entrada na última fase do ciclo vital". A autora descreve a atual medicina anti-envelhecimento como "fonte de ilusôes (e polpudos lucros)" ( NERI, 2007, p. 34), entendendo que a indústria cosmética mobiliza um grande contingente de conhecimentos para promover o esforço de atenuar e adiar ao extremo os processos de envelhecimento.

Tendo em mente o relevante papel das produções midiáticas nas disputas pelas atribuições sociais de sentidos, iniciamos esta investigação sobre a velhice elencando algumas tramas e personagens marcantes e elegemos a última década e meia como recorte temporal da pesquisa. Assim sendo, nossa cartografia se volta para as produçóes de 2000 a 2015 e procura articular as personagens ao contexto social no qual se inserem.

Nos parágrafos que se seguem, contextualizamos a telenovela no cotidiano dos brasileiros, traçamos um breve relato do desenvolvimento deste gênero ficcional no Brasil, mapeamos - assumidamente de modo ainda incipiente - os modos de apresentação da velhice na teledramaturgia e em seguida focalizamos alguns de seus elementos por meio tramas e personagens memoráveis, em um recorte que privilegia a discussão sobre a velhice feminina.

\section{A telenovela e o cotidiano}

Para melhor compreender a relaçáo entre telenovela e vida social em nosso país, Paula Simóes e Vera França ressaltam, com propriedade, que

a telenovela ocupa, (...), um importante lugar na cultura e na sociedade brasileiras. Ela constrói um cotidiano na tela em estreita relação com a realidade social em que se situa, trazendo para a construção das personagens as preocupaçóes, os valores e temas que perpassam o cotidiano dos telespectadores. (FRANÇA E SIMÓES, 2007, p. 52).

Além de desempenharem papel de destaque no entretenimento e lazer cotidianos, as telenovelas atuam de modo significativo na formaçáo social dos gostos e na consolidaçáo de práticas sociais, como o consumo material e simbólico. É sabido que, de um modo geral, a mídia interpreta a produção e socializa para o consumo. No caso específico das telenovelas, neste exercício nem sempre explícito de educação informal propiciado pela teleficçáo, temos que a cenografia, o enredo, o elenco e os personagens funcionam como vitrines por meio dos quais os telespectadores podem apreender estilos de vida e modos de ser atrelados aos mais variados bens, valores e práticas sociais.

Entendida como um processo complexo que envolve produção, distribuição e recepção de mensagens, a Comunicação diz respeito à vinculação social em um contexto de disputas em torno da produção de significados. Como se sabe, os meios de comunicação participam de forma importante da constituição das subjetividades ao expressar em suas produções aquele conjunto de valores, saberes e práticas sociais que funcionam como matrizes culturais.

Para Guareschi (2010), é fundamental pensar o social como relação, uma rede que possui um direcionamento voltado para o singular e outro em direção ao múltiplo. Ao discorrer sobre a Teoria das Representaçôes 
Sociais, que fundamenta o campo da Psicologia Social, o autor ensina que "o social (...) constitui o processo de mediação na complexidade entre o mundo interno e externo, entre o individual e o coletivo, entre o psiquismo individual e a realidade psíquica social externa." (VERONESE e GUARESCHI, 2010, p. 80-81).

Nossa análise parte da premissa de que as imagens e discursos da mídia afetam a maneira como nossas sociedades se relacionam com o envelhecimento, reforçando ou rechaçando estereótipos e preconceitos. É nesse sentido que a discussão sobre a temática do envelhecimento na teledramaturgia brasileira pretende contribuir para adensar nossa compreensão sobre experiência e cotidiano, ao discutir o papel da mídia na produção dos sentidos sobre a velhice que circulam no campo social.

Consideramos que durante o período em que a telenovela está sendo exibida, existe uma apropriação de vários aspectos daquilo que está acontecendo na trama: moda, música, determinadas expressões linguísticas, determinados comportamentos, jeitos de ser etc. No entanto, não se pode afirmar que isso se incorpora na populaçáo. No caso da telenovela, os receptores desempenham papel ativo na construção dos sentidos deste produto cultural ao (re)vestirem-no de significado, nem sempre em consonância com o convencional ou o esperado.

Mesmo reconhecendo o evidente desnível de forças entre a indústria cultural e o público - algo que as redes sociais na internet não tornaram obsoleto como querem fazer crer certas leituras apressadas das reconfiguraçóes em curso nas assim chamadas mídias sociais - os embates em torno da produção de sentidos podem ocasionar o tensionamento e mesmo o eventual rompimento de caminhos pré-estabelecidos de significados, a atualização de leituras e, eventualmente, a abertura de trilhas que poderão desaguar em reformulaçóes culturais mais expressivas. Por esta razão são fundamentais as contribuiçóes trazidas por pesquisas empíricas em Comunicação. Trata-se de elementos chave para compreendermos os modos como a telenovela participa das permanentes disputas em torno da produção de sentidos em nossos dias.

O significado da comunicação, as significaçôes dos produtos culturais, incluindo os produtos dos meios de comunicação e em particular a telenovela, relacionam-se com o cotidiano do sujeito receptor, com suas práticas culturais, com as marcas que influenciam seu modo de ver e praticar a realidade. São aquelas que lhe dão a segurança necessária para estruturar, organizar e reorganizar a percepção da realidade, reconstruindo-a, com destaques ou apagamentos, de acordo com sua cultura. Essas práticas culturais constituem as mediaçôes, que interferem em todo o processo comunicacional, balizando-o.

Sem descurar do viés ideológico, compreende-se que o discurso midiático engendra uma carga afetiva que matiza nossas interaçóes no mundo, modulando afetivamente a experiência do cotidiano. Reconhecendo o papel ativo do receptor da comunicação e o caráter dialético da conformação social dos discursos, este estudo considera a dimensão afetiva do conteúdo simbólico acerca da velhice acionado nas narrativas teleficcionais que ora reforçam e ora desafiam estereótipos, convenções e preconceitos. 


\section{A telenovela}

Alguns pontos são importantes para a aproximação da telenovela como objeto de estudo: sua história, a constituição das telenovelas socioculturais, sua condição de produto intergêneros e interclasses e a influência de mão dupla que se estabelece entre esse produto cultural e a sociedade em que se insere. Por esses pontos passamos neste tópico.

A telenovela continua a ser o mais importante produto da indústria cultural brasileira. O que garante tal asserção é sobretudo o fato de se tratar da mesma estrutura narrativa que acompanha a humanidade desde sempre e na qual aparecem duas pessoas que se amam e um grande obstáculo: uma outra pessoa, classes sociais diversas, faixas etárias díspares etc. Ocorre que ela é contada do modo original, de acordo com a sociedade e o avanço das tecnologias. Distingue-se também pelo fato de construir-se sob a forma de ficção seriada, cujos ganchos, ao final dos capítulos, têm o objetivo de manter a audiência.

Se a importância desse produto cultural é fato incontestável, o menosprezo da academia, por um longo tempo, parece ter significado uma aprovação silenciosa travestida de desaprovação debochada das releituras e atualizaçôes que a telenovela realiza da realidade social na qual se inscreve. Compete à Universidade, lugar da reflexão e da crítica, produzir e divulgar novos olhares, científicos e não de senso comum, dialógicos e não maniqueístas sobre os produtos da indústria cultural.

\section{Um pouco de história}

A narrativa acompanha o ser humano desde que o homem adquiriu a faculdade de representar. Em texto clássico, Milly Buonanno enfatiza a densidade semântica do termo narrativa que, na sua acepção alargada, pode ser utilizado para designar

$$
\begin{aligned}
& \text { qualquer forma de conto de imaginação que a história humana tenha conhecido } \\
& \text { da pintura rupestre à poesia épica, às obras teatrais, aos diversos gêneros de prosa } \\
& \text { literária; da narração cinematográfica, aos quadrinhos e aos desenhos animados. } \\
& \text { Contemporaneamente, o termo fiç̧ão tende a ser utilizado em duas principais e } \\
& \text { específicas acepçôes: a primeira se circunscreve, no âmbito literário, à produçáo em } \\
& \text { prosa de romances e novelas; a segunda se refere, no âmbito da mídia, à produçáo } \\
& \text { narrativa de televisão, ou ficção televisiva. (BUONANNO, 1996, p.19). }
\end{aligned}
$$

O narrador sempre ocupou lugar de destaque nas sociedades: quer seja ao redor da fogueira, quer seja nas cortes, quer seja nos jornais, no rádio, na televisão, na internet.

$\mathrm{Na}$ América Latina, o ponto de partida dessa dramaturgia é Cuba. O êxito da radionovela cubana teve seu ponto alto nos dramaturgos, entre os quais se destaca Félix B. Caignet, autor de Chan Li Po, A serpente vermelha, entre outras, e da mais conhecida de todas, O Direito de Nascer, a qual, no Brasil, foi apresentada no rádio, com enorme êxito. Além das transmissóes radiofônicas, eram produzidos, à época, livretos, que continham os capítulos da novela e eram vendidos em bancas de jornais. $\mathrm{O}$ texto recebeu ainda duas versóes para telenovela (Tupi, 1965 e 1978). 
No Brasil, a primeira telenovela diária chamava-se 2-5499 Ocupado e aconteceu em 1963. Foi escrita por Dulce Santucci baseada em original de Alberto Migré. Teve Glória Menezes e Tarcísio Meira nos papéis principais e foi veiculada pelo Canal 9 (Excelsior, Sáo Paulo) e Canal 2 (Rio de Janeiro). Conforme registros da época, sabe-se que desde então o gênero já demostrava grande poder de penetração junto ao grande público, tendo sido o usuário da linha telefônica presente no título da telenovela obrigado a solicitar a mudança de seu número.

A telenovela brasileira tem se revelado um produto antropofagicamente construído pelos brasileiros, que deglutiram as influências do circo, do folhetim e do cordel, da soap opera e dos cubanos. Hoje já se pode percebê-la em fases: da brasilidade que Beto Rockfeller instalou às novelas críticas dos tempos da ditadura, sobretudo década de 1970 e princípios da década de 1980, quando dramaturgos como Dias Gomes e Lauro César Muniz, cassados do teatro pela ditadura, abrigam-se na televisão dividindo o país em povoados onde se exercitava a crítica e se pregava a liberdade, até a telenovela contemporânea, escrita e dirigida por uma equipe e não mais por um único autor e diretor, com todas as vantagens e problemas daí decorrentes.

Nas primeiras telenovelas - início da década de 1960 -, as quais podemos chamar tradicionais, a concepção de mundo era maniqueísta, dividindo os personagens entre bons e maus, sem nuances e sem possibilidade de mudança. Os diálogos eram ainda rudimentares e as situações, baseadas em estereótipos consagrados por todas as classes sociais: o homem é o que pensa e decide e a mulher é um ser emocional dele dependente; existem profissóes só masculinas e só femininas; os médicos são sempre abnegados e os políticos, corruptos; a família era sempre do tipo nuclear, com pai, mãe e filhos.

Diferentemente, passamos a ter no elenco das telenovelas seguintes, às quais podemos chamar de socioculturais, a presença da complexidade social: as personagens deixam de ser planas - só boas ou só más - e passam a construir seu próprio destino em interação com o contexto socioeconômico-cultural, à vista do telespectador e com sua influência. Abordam-se novas temáticas e se modifica o tratamento dado ao melodrama e à estruturação dos capítulos. A família vai se configurar de modos múltiplos, incluindo os novos arranjos familiares. Nem sempre são punidos a corrupção e o mau caráter. Talvez o mais importante, cria-se um número grande de subtramas que passam a ter importância no desenvolvimento da história, gerando a possibilidade de discussão múltipla de uma ampla variedade de temas. A história de amor, central, não desaparece, mas se torna muito mais complexa. Sendo assim, a telenovela produzida pela Rede Globo destacou-se como um produto acessível e como um espaço ideal para açôes de propaganda e marketing, atraindo expressivo percentual das verbas publicitárias e consolidando-se também como importante um produto de exportação.

Embora hoje se possa acessar outros tipos de teledramaturgia, como as novelas de cunho religioso produzida pela Rede Record, focalizamos neste estudo a telenovela que mantém estreitas relaçóes com o dia a dia da sociedade da qual emerge, com a qual mantém diálogo permanente em todo o percurso de sua realização enquanto produto cultural. Esta é uma telenovela que se constitui na interação com o social e que colabora na constituição dessa mesma sociedade. 
Com base em uma seleção personagens e tramas memoráveis, passamos a apresentar uma cartografia inicial comentada da velhice na telenovela brasileira. Iniciamos o percurso na icônica $O$ Direito de Nascer, exibida na década de 1960. Nesta trama, encontramos uma velha negra que sacrifica sua vida para tomar conta do filho de sua jovem patroa. Trata-se de uma personagem bondosa e também extremamente corajosa, pois para tanto teve que enfrentar o temido D. Rafael, pai da jovem.

\section{Mamãe Dolores e O Direito de Nascer}

Baseada em texto do cubano Felix Caignet, O Direito de Nascer deu o tom da telenovela latinoamericana e foi sucesso na televisão brasileira no início da década de 1960. Produzida pela hoje extinta TV Tupi, a trama enfocava a questão do direito à vida na estrita vigilância da procriação na família patriarcal. Na personagem Mamáe Dolores, interpretada pela atriz Isaura Bruno - uma das raras negras na televisão brasileira à época - temos o estereótipo da mulher humilde de índole nobre e bom coração.

Tingida pelo racismo, cuja nefasta presença ainda se constata na sociedade brasileira, a personagem de Isaura Bruno é modelada na imagem da negra ama de leite, aquela que seria naturalmente talhada para ser mãe; no caso, a santa mãe da abnegação, do sacrifício, da bondade absoluta. Sem pretender tomar para si o protagonismo das classes privilegiadas que aprendeu desde sempre a obedecer e servir, Dolores se comove com a triste sina do bebê enjeitado e arrisca a própria vida para salvar o neto bastardo do seu patrão. Tendo fugido com o bebê cuja morte havia sido ordenada pelo despótico viláo D. Rafael Zamora de Juncal, a velha empregada passa a criá-lo como se fosse seu próprio filho.

Característico das telenovelas tradicionais, o enredo passa ao largo das regras da verossimilhança ao tratar como plausíveis as diferenças de raça e idade entre mãe e filho. No desfecho dramático que encerra a trama, o jovem médico Albertinho salva a vida de um velho paciente, que agonizava, sem suspeitar que tratava-se do avô que teria tentado impedi-lo de vir ao mundo.

Como dissemos, a partir da década de 1970 a teledramaturgia brasileira deixa para trás o modelo tradicional herdado das radionovelas cubanas e passa a produzir textos em diálogo com a sociedade. Desse modo, a telenovela se firma como um universo onde circulam conteúdos reelaborados a partir das normas da ficção em sintonia direta com aquilo que está acontecendo no contexto social. As telenovelas atuais enfocadas em nosso estudo abordam temas que fazem parte do contexto vivido pelo público. Nessa argumentaçáo, sublinham o aspecto da verossimilhança que novelas anteriores, como se viu, não se preocupavam em exibir. Respeitando o recorte cronológico estabelecido para a pesquisa, voltamos agora a atenção para as telenovelas produzidas pela Rede Globo nesta primeira quinzena dos anos 2000.

\section{Entra em cena a violência contra o idoso}

Coerentes com a característica sociocultural da teledramaturgia mencionada acima, destacamos Mulheres Apaixonadas, de 2003, na qual a questão do velho aparece com grande destaque, ainda que em uma subtrama. Trata-se de 
um casal de idosos interpretados por Carmem Silva e Oswaldo Louzada, que por necessidade vai viver na casa do filho e passa então a ser consistentemente maltrataddo pela neta. A comoção causada pela humilhaçáo e os maus-tratos vividos pelos simpáticos Leopoldo e Flora teria contribuído para colocar em debate junto ao grande público o tabu da violência doméstica ao focalizar o espinhoso tema da violência contra os idosos nas famílias brasileiras.

Segundo dados da Secretaria Especial dos Direitos Humanos, "os conflitos intergeracionais, as várias formas de violência física e emocional, as negligências de cuidados" variam no tempo segundo classe social, etnia e gênero, evidenciando "o desejo social de se ver livre dos mais velhos" (MINAYO, 2005, p. 11). Em sua maioria os abusos são cometidos por familiares, dentro do ambiente doméstico onde, ainda segundo o documento, se pode encontrar "castigos em cárcere privado, abandono material, apropriação indébita de bens, pertences e objetos, tomada de suas residências, coaçôes, ameaças e mortes." (Idem)

Em meio às tensões e conflitos deflagrados pela situação de dependência em um lar multigeracional de classe média, a narrativa ficcional de Mulheres Apaixonadas trouxe a público, ainda, a delicada questão do empobrecimento pós-aposentadoria lado a lado com as demandas do amparo e cuidados com os idosos por parte de pessoas mais jovens que nem sempre os compreendem e respeitam. Na trama, Flora e Leopoldo contribuem para o seu sustento na casa do filho, cujo orçamento apertado não lhe permite condiçóes de arcar com as despesas extras decorrentes da chegada dos pais. Os personagens haviam sido artistas em sua mocidade e, por isso, a soluçáo do problema virá com sua transferência para o Retiro dos Artistas, casa da acolhimento que a novela ajudou a tornar conhecida do grande público.

\section{A sexualidade dos idosos em cena}

Em termos do maior protagonismo dos mais velhos na telenovela, podemos afirmar que temos um largo passo adiante com Belissima (2005), que traz Fernanda Montenegro no papel de uma septuagenária matriarca rica, poderosa e cruel. A personagem está alinhada com o fenômeno da feminização da velhice, ocasionado pela maior longevidade das mulheres em relação aos homens. Esse é um fenômeno observado não apenas no Brasil mas também em outras partes do mundo. Como consequência, tem-se uma clara prevalência de idosas em relação ao número de idosos, sendo que muitas delas são economicamente ativas e exercem a posição de chefes de família. Em Belíssima, esta personagem conduz com sucesso uma empresa de porte internacional, herança de sua filha morta prematuramente. Bia Falcão, era esse seu nome, tem pulso de ferro e desperta forte antipatia por seu jeito arrogante, perfeccionista e autoritário. Educa seu neto e neta, a quem não perdoa por resistir obstinada às suas investidas para torná-la igual à mãe. Guarda em segredo o luto relativo à primeira filha da qual teve que abrir mão na juventude, além de suas próprias inseguranças advindas de uma rejeição amorosa no passado.

Esta é uma personagem muito bem desenhada dramaturgicamente, uma vilá cheia de nuances envolta em uma trama costurada por lances surpreendentes, ao estilo do gênero. Quase ao final da novela, a personagem é 
supostamente vitimada em um acidente de carro, mas tudo não passou de encenação. Coerente com a sina da megera que é amada pelo público, Bia Falcão retorna à trama e termina a novela impune fora do país e junto com seu jovem amante, apesar de todas as maldades e falcatruas que cometeu.

Belissima entra na história da teledramaturgia como pioneira a trazer para a telinha a mulher idosa e sexualmente ativa. Outras novelas que se seguiram a esta também trataram desta temática, ainda que por outros ângulos. Em Passione, de 2011, Cleyde Yáconis se notabiliza como a excêntrica quatrocentona Brígida Gouveia, que durante anos manteve um tórrido relacionamento extraconjugal com o motorista enquanto incentivava as investidas do jardineiro. Após divorciar-se de um casamento conturbado, vem a se casar com o motorista enquanto mantém o jardineiro como amante.

O triângulo amoroso vivido na trama com Diógenes (Elias Gleiser) e Benedetto (Emiliano Queirós) é apresentado como divertido, um modo de tornar palatável um assunto tabu pelas regras do conservadorismo. Tendo em mente a pervasiva combinação entre machismo e idadismo à qual nos referimos anteriormente, somos levadas a ponderar sobre a sempre tênue a fronteira entre humor e o deboche no tratamento dado à temática da sexualidade dos mais velhos.

Outras personagens femininas que merecem nossa atenção neste folhetim são Gemma, Clô e Valentina. Interpretada por Aracy Balabarian, Gemma Mattoli é uma típica mamma italiana. No final da trama ganha o amor de Antero Gouveia (Leonardo Villar), agora divorciado da incorrigível Brígida. Percebe-se nesse desfecho o conservadorismo que fixa nos papeis de mãe e esposa a mulher - madura ou não - considerada virtuosa. Além de Brígida Gouveia, que escapa a este estereótipo, a novela apresenta outro contraponto na espalhafatosa Clô Silva e Souza. Esta personagem de Irene Ravache mantém com o marido (Olavo/Francisco Cuoco) uma relação de alta voltagem erótica, apimentada por apelidinhos, sex toys e práticas sensuais variadas. Trata-se de um modo de vida que escapa do que convencionalmente se costuma associar a um casal da terceira idade, ou fase inicial da velhice. Funciona como índice da heterogeneidade dos modos de experimentar o envelhecimento no mundo atual. Já Valentina Miranda, a personagem de Daisy Lúcidi nesta trama, alude à antiquíssima tradição das casas de prostituição. Como uma cafetina, a aparentemente simpática Valentina explora as netas e vive às turras com uma delas, que a xinga de velha porca, explicitando toda a carga semântica negativa atrelada ao termo velha. Em um desfecho que atende às normas sociais vigentes e apazigua a reação do público, a personagem termina atrás das grades.

Em diálogo com as reflexôes de Debert (1999) que contribuem para embasar este estudo, indagamos de que modo os meios de comunicação "como construtores de mundo, por meio da linguagem, das escolhas e representaçóes de pessoas e coisas", contribuem para "a reprivatização da velhice (que) desmancha a conexão entre a idade cronológica e os valores e os comportamentos considerados adequados às diferentes etapas da vida” (DEBERT, 1999, p. 65, 67). Como 
veremos nos dois casos discutidos a seguir, o tratamento ficcional dos muitos modos de se experimentar a sexualidade na velhice revolve arraigados preconceitos e por vezes encontra forte resistência por parte do público telespectador.

Em 2014, Amor à Vida trouxe em uma de suas subtramas o romance entre Bernarda e Lutero, interpretados por Nathalia Timberg e Ary Fontoura. A família dela - e possivelmente parte do público - se choca ao tomar conhecimento que haviam dormido juntos. O viláo Félix, neto de Bernarda, acusa-a de haver se transformado em vovó periguete. O bordão fez sucesso junto ao público, que não obstante aprovou o casamento transcorrido em grande estilo nos capítulos finais da trama. Esta novela quebrou paradigmas ao tratar abertamente da vida sexual na velhice e expor a carga de preconceito atrelado a esta questão.

Contrariando o senso comum sobre o declínio dos apetites e aptidóes para o sexo no passar dos anos, a vida sexual ativa tem sido promovida como exigência para o envelhecimento bem sucedido. Conforme argumentam Debert e Brigueiro, "os processos de erotização da velhice" (DEBERT e BRIGUEIRO, 2012, p.50), são também propagados pela mídia e colocam a ênfase na saúde, o que de certo modo desvincula o sexo das práticas puramente hedonistas. "É o erotismo politicamente correto que parece permitir que a beleza e a atração física possam ser colocadas num segundo plano" (Idem) em prol de uma sensualidade difusa que perpassa a epiderme como um todo. Esta abordagem vincula a sexualidade aos cuidados de si e à qualidade de vida na velhice.

Babilônia (2015), novela que teve no primeiro capítulo uma cena de beijo entre duas senhoras octogenárias, que vivem juntas um relacionamento homoafetivo há muito tempo e agora resolveram casar-se. Protagonizada por Fernanda Montenegro e Nathália Timberg, a cena não foi tâo bem recebida pelo público. Por essa cena (talvez principalmente), mas também por outros aspectos a novela não agradou. Toda a história foi modificada em busca de maiores índices de uma audiência que majoritariamente pressupóe a heterossexualidade como norma.

\section{Considerações finais}

Se em outras épocas a velhice era escamoteada pela conspiração do silêncio de que falou Simone de Beauvoir (1976), adquire crescente relevância dentre as questóes sociais e políticas que caracterizam a contemporaneidade. Devido ao seu protagonismo no cotidiano de públicos de diferentes segmentos, a programação televisiva - com destaque para a telenovela - contribui para a discussão sobre tópicos controversos da velhice que são silenciados ou considerados tabus, tais como a violência doméstica, a sexualidade e as identidades homoafetivas, dentre outros.

Ao considerarmos a baixa incidência de imagens do idoso na mídia em geral, observamos ao longo da última década e meia uma gradual transformação, ainda que discreta, desta situação na teleficção brasileira. Além do ineditismo de um casal de idosas lésbicas em uma recente telenovela do horário nobre, a Globo investe na tematização do envelhecimento em outras de suas produçóes, tais como a mini série estrelada por atores e atrizes mais velhos que recebeu o sugestivo título de Os Experientes. 
Decididamente, parece-nos que estamos experimentando uma transição no tratamento dispensado pela nossa teledramaturgia à velhice e ao envelhecimento. Ainda que se queira fugir de uma interpretação maniqueísta deste conteúdo ficcional com base em julgamentos de valor acerca de quais tipos de representaçáo poderiam ser considerados como positivos ou negativos, a presença estereotipada do velho em papéis secundários hoje convive com personagens marcantes como protagonistas. Em muitos casos, trata-se de modelos contra hegemônicos que contestam o senso comum da debilidade e da desvalorização social conferidas aos mais velhos. Entendemos que este novo olhar que parece estar sendo lançado em direção aos modos de ser e experimentar o envelhecimento seria motivado, ao menos em parte, pela necessidade de estabelecer pontos de contato com um segmento de mercado que se torna majoritário e que passa a ser percebido como um filáo comercialmente promissor.

No campo da Comunicação, começa a se reverter a parca atenção tradicionalmente conferida ao estudo deste tema. Ao atentarmos nesta discussão para a dimensão sociocultural da velhice, é indispensável destacar a importância dos meios de comunicação na constituição das identidades culturais dos mais velhos e nas variadas formas de lidar com a velhice, tanto por parte dos idosos, quanto por suas famílias e outras instâncias da sociedade. Como aponta Anita Neri, "As atitudes em relação à velhice são socialmente aprendidas ao longo de toda a vida” (NERI, 2007, p. 35). Tendo argumentado que as atitudes são produtos de complexos processos afetivos e social-cognitivos, a estudiosa ensina que esta aprendizagem se dá pela experiência direta da vivência da própria velhice e/ou a convivência com idosos. Variadas modalidades de experiência simbólica também concorrem para a nossa aprendizagem, tais como obras de ficção, meios de comunicação, publicidade, religião etc. Sendo assim, podemos pensar a telenovela como instância pedagógica informal no cotidiano de grandes contingentes do público.

Em vista desta constatação, é relevante indagar: até que ponto a nossa produção televisiva contempla a heterogeneidade de modos de viver a velhice no contemporâneo? Qual o papel ficção televisiva e, mais notadamente, qual a mediação da telenovela na constituição dos sentidos sociais do envelhecimento em nossos dias? De que maneira os afetos produzidos pelas imagens e discursos em circulação matizam as experiências, as práticas e as atitudes em relação à velhice no cotidiano atual?

Sem pretender trazer respostas a essas indagaçóes, visamos promover uma reflexão sobre como tem sido trabalhada a velhice e, em especial, a velhice feminina nas telenovelas brasileiras nesta primeira década e meia do século XXI. Reforçando o papel social da produção acadêmica, pretendemos despertar o interesse e, quem sabe, envolver outras vozes do campo da Comunicação neste importante e oportuno debate. 


\section{Referências bibliográficas}

BEAUVOIR, Simone de. A velhice: realidade incômoda. São Paulo: Difel, 1976.

BUONANNO, Milly. Leggere la fiction. Narrami o diva revisitata. Napoli: Liguori Ed., 1996.

DEBERT, Guita G. e BRIGUEIRO, Mauro. Fronteiras de gênero e a sexualidade na velhice. Revista Brasileira das Ciências Sociais. vol.27, no.80, 2012, p. $34-54$.

DEBERT, Guita G. A antropologia e o estudo dos grupos e das categorias de idade. In: LINS DE BARROS, Myriam M. (Org.). Velhice ou terceira idade? Estudos antropológicos sobre identidade, memória e política. Rio de Janeiro: Ed. FGV, 2006, p. 49 - 68.

DEBERT, Guita G. A reinvenção da velhice: socialização e processos de reprivatização do envelhecimento. São Paulo: Edusp, 1999.

FRANÇA, Vera e SIMÓES, Paula. Telenovelas, telespectadores e representaçóes do amor. ECO-PÓS, v.10, n.2, julho-dezembro 2007, p. 48-69.

MOSCOVICI, Serge. Representaçôes sociais: investigações em psicologia social. Petrópolis: Vozes, 2003.

MINAYO, Maria Cecília. Violência contra os idosos: o avesso do respeito à experiência e à sabedoria. Brasília: Secretaria Especial dos Direitos Humanos, 2005.

NERI, Anita L. (Org.). Idosos no Brasil: vivências, desafios e expectativas na terceira idade. São Paulo: Ed. Fundação Perseu Abramo, Edições SESC SP, 2007.

VERONESE, Marília V. e GUARESCHI, Pedrinho. Introdução: articulando representaçóes sociais e cotidiano. In: VERONESE, Marília V. e GUARESCHI, Pedrinho A. (Orgs.). Psicologia do cotidiano: representaçôes sociais em ação. Petrópolis: Vozes, 2007, p. 9 - 16.

\section{Notas}

1. Uma versão deste trabalho foi apresentada ao GP Ficção Seriada do XXXVIII Congresso Brasileiro de Ciências da Comunicação, Intercom 2015. 